\title{
From Monodisciplinary via Multidisciplinary to an Interdisciplinary Approach Investigating Air-Sea Interactions - a SOLAS Initiative
}

Christa Marandino, Erik van Doorn, Natasha McDonald, Martin Johnson, Bülent Açma, Emilie Brévière, Hanna Campen, Silvina Carou, Emilio Cocco, Sonja Endres, Nathalie Hilmi, Frances Hopkins, Peter Liss, Frank Maes, Monica Mårtensson, Johannes Oeffner, Mary Oloyede, Andrew Peters, Birgit Quack, Pradeep Singh \& Helmuth Thomas

To cite this article: Christa Marandino, Erik van Doorn, Natasha McDonald, Martin Johnson, Bülent Açma, Emilie Brévière, Hanna Campen, Silvina Carou, Emilio Cocco, Sonja Endres, Nathalie Hilmi, Frances Hopkins, Peter Liss, Frank Maes, Monica Mårtensson, Johannes Oeffner, Mary Oloyede, Andrew Peters, Birgit Quack, Pradeep Singh \& Helmuth Thomas (2020): From Monodisciplinary via Multidisciplinary to an Interdisciplinary Approach Investigating Air-Sea Interactions - a SOLAS Initiative, Coastal Management, DOI: 10.1080/08920753.2020.1773208

To link to this article: https://doi.org/10.1080/08920753.2020.1773208

$$
\text { 曲 Published online: } 05 \text { Jun } 2020 .
$$

Submit your article to this journal ๘

Q View related articles ¿

View Crossmark data ¿ 


\section{From Monodisciplinary via Multidisciplinary to an Interdisciplinary Approach Investigating Air-Sea Interactions - a SOLAS Initiative}

Christa Marandino ${ }^{a}$, Erik van Doorn ${ }^{b}$, Natasha McDonald ${ }^{a, c}$, Martin Johnson $^{d}$, Bülent Açma ${ }^{e}$, Emilie Brévière ${ }^{a, f}$, Hanna Campen ${ }^{a}$, Silvina Carou ${ }^{g, h}$, Emilio Cocco ${ }^{i, j}$, Sonja Endres ${ }^{a, k}$, Nathalie Hilmi', Frances Hopkins ${ }^{m}$, Peter Liss ${ }^{n}$, Frank Maes ${ }^{\circ}$, Monica Mårtensson ${ }^{p}$, Johannes Oeffner ${ }^{q}$, Mary Oloyede ${ }^{r}$, Andrew Peters ${ }^{c}$, Birgit Quack ${ }^{a}$, Pradeep Singh ${ }^{s}$, and Helmuth Thomas ${ }^{t}$

\begin{abstract}
${ }^{a}$ Marine Biogeochemistry, GEOMAR Helmholtz Centre for Ocean Research Kiel, Kiel, Germany; ${ }^{b}$ Walther Schücking Institute for International Law, Kiel University, Kiel, Germany; 'Bermuda Institute of Ocean Sciences, Ferry Reach, St. George's, Bermuda; ${ }^{d}$ Centre for Ocean and Atmospheric Sciences, University of East Anglia, Norwich, UK; 'Unit of Southeastern Anatolia Project, Faculty of Economics, Anadolu University, Eskisehir, Turkey; ${ }^{\mathrm{f}}$ Oceanography Department, Swedish Meteorological and Hydrological Institute, Norrköping, Sweden; ${ }^{9}$ Climate research Department, Environment and Climate Change Canada, Toronto, Canada; ${ }^{\mathrm{h}}$ Atmospheric Research and Environment Branch, World Meteorological Organization, Geneva, Switzerland; 'Faculty of Communication Science, University of Teramo, Teramo, Italy; ${ }^{j}$ Communications Department, The American University of Rome, Rome, Italy; ${ }^{k}$ Maritimes Cluster Norddeutschland, WTSH - Business Development and Technology Transfer Corporation of SchleswigHolstein, Kiel, Germany; 'Environmental Economics Department, Centre Scientifique de Monaco, Monaco; ${ }^{m}$ Marine biogeochemistry and Ocean Observations Department, Plymouth Marine Laboratory, Plymouth, UK; ${ }^{n}$ Centre for Ocean and Atmospheric Sciences, School of Environmental Sciences, University of East Anglia, Norwich, UK; ${ }^{\circ}$ Maritime Institute, Faculty of Law and Criminology, Ghent

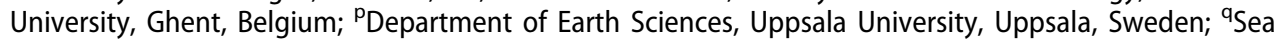
Traffic and Nautical Solutions, Fraunhofer Center for Maritime Logistics and Services, Hamburg, Germany; 'Department of Chemistry, Covenant University, Ota, Nigeria; ${ }^{5}$ Governance for the Environment and Society, Institute for Advanced Sustainability Studies, Potsdam, Germany; ${ }^{\text {Institute for }}$ Coastal Research, Helmholtz-Zentrum Geesthacht, Centre for Materials and Coastal Research, Geesthacht, Germany
\end{abstract}

\section{KEYWORDS}

Air-sea interactions; policy across the air-sea interface; shipping and biogeochemistry; social science; SOLAS science and society; valuing ocean carbon 
and the ocean's role; air-sea interactions, policy and stewardship; and, air-sea interactions and the shipping industry.

\section{Introduction}

The consumption of the ocean's resources affects a growing number of people directly, but only a small percentage of the world's population has a direct experience of the ocean's tangibility (Helmreich 2009), especially regarding the open ocean. It appears logical that the general population must know something about the ocean, its various natural and social interconnections, and its governance, in order to engage in ocean stewardship. This is a challenge in which science has an important mediating role to play. Given the rapid predicted and observable changes in the Earth's climate occurring now and into the future, a more comprehensive approach to scientific research is needed to inform policy decisions and to effectively respond to climate change. This, in part, is what has driven the development of the Future Earth Ocean Knowledge-Action Network. Expertise by both natural and social scientists has long been sought out by policymakers and stakeholders; in the recent past, however, a notable disconnect between the two sets of disciplines remains, often resulting in an imbalanced perspective or incomplete understanding of the issue. As such, many researchers recognize the need for a more holistic approach to climate science. A few review papers have identified the need for greater collaboration and for interdisciplinary higher education, in which knowledge is integrated across disciplines (Brink, Hengeveld Geerten, and Tobi 2020; Fischer, Tobi, and Ronteltap 2011). However, while attempts have been made to bridge the divide between the natural and social sciences, the approaches have not yielded the fully balanced contribution needed for truly comprehensive understanding. Both Fischer, Tobi, and Ronteltap (2011) and Brink, Hengeveld Geerten, and Tobi (2020) conducted systematic searches for research papers utilizing interdisciplinary approaches between the natural and social sciences. In the Fischer, Tobi, and Ronteltap (2011) study, the search provided only 247 articles, and upon inspection of the content, only 81 were found to be relevant. The review study found that there were several obstacles to truly interdisciplinary efforts, including structures created by academic institutions, especially tenure-track criteria, which generally promote disciplinary work. Nearly a decade later, Brink, Hengeveld Geerten, and Tobi (2020) found almost twice as many papers, 467, but still only 77 contained detailed information on interdisciplinary measurements. They concluded that interdisciplinary measurement models of sustainability were "near-unique".

Within the natural sciences, the formation of global working groups (e.g., Scientific Committee on Oceanic Research [SCOR] working groups) has been a useful and efficient way to execute collaborative science and to deal with complex, multidisciplinary issues. However, these types of working groups, in which small diverse committees of experts meet in person to hash out specific issues, have not been common in attempts to bridge the natural and social sciences. Typically, either one token social scientist is entrained by a group of natural scientists, or vice versa. Alternatively, natural scientists commonly complete one part of a project, while social scientists separately complete the 


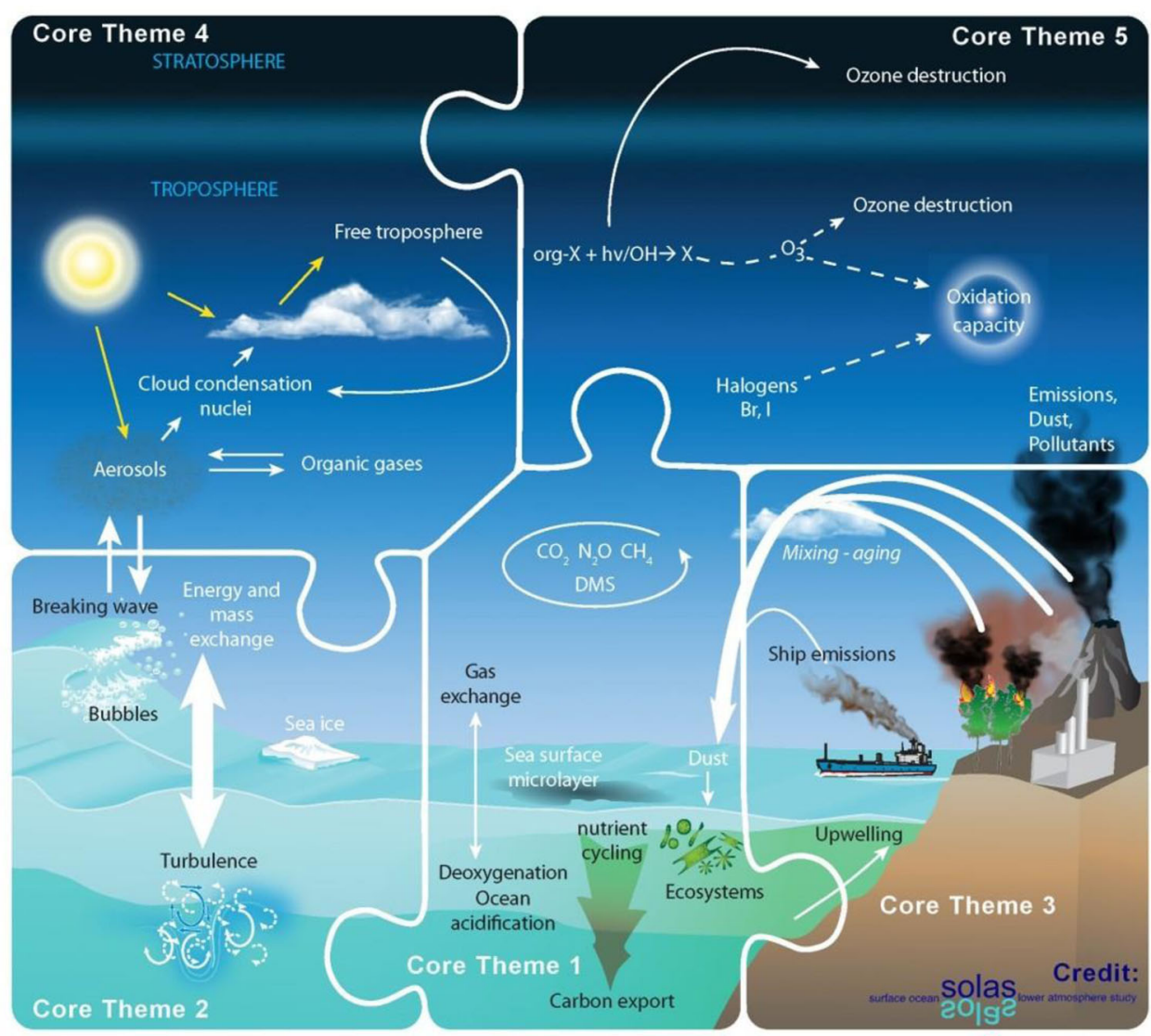

Figure 1. Conceptual diagram of SOLAS scientific foci. For more information about the current SOLAS science plan, please visit https://www.solas-int.org/science.html. Figure from Brévière (2016).

other part, their findings are then hastily combined at the end. Additionally, securing joint funding for collaborations from both the natural and social sciences is often difficult. Furthermore, ostensibly joint efforts frequently are carried out separately in practice. This is especially true in climate change research, where atmospheric and ocean sciences data is acquired by natural scientists but analyzed separately in the context of economic and legal issues. There are, however, notable exceptions to this pattern of limited interaction amongst disciplines. Ocean acidification research, an example of best practice, has often been interdisciplinary, leading to important policy decisions by the United Nations, USA, and other nations (Bailey et al. 2016).

The value of interdisciplinary, and even transdisciplinary, work on specific marine issues is well recognized; however, its implementation is not straightforward (Glavovic et al. 2015). Despite this, the crucial need to transcend disciplinary boundaries is seen as a conditio sine qua non for future marine research (Markus et al. 2018). Challenges arise as marine research has been dominated to date by natural sciences, a realm into which social science has not entered, traditionally (Palsson et al. 2013). In fact, the sea is little researched in a sociology context (Cocco 2013), perhaps because humans inhabit the land and social studies have focused on a terrestrially based, state-centered understanding of society (Wimmer and Glick Schiller 2002; Chernilo 2007). Moreover, 


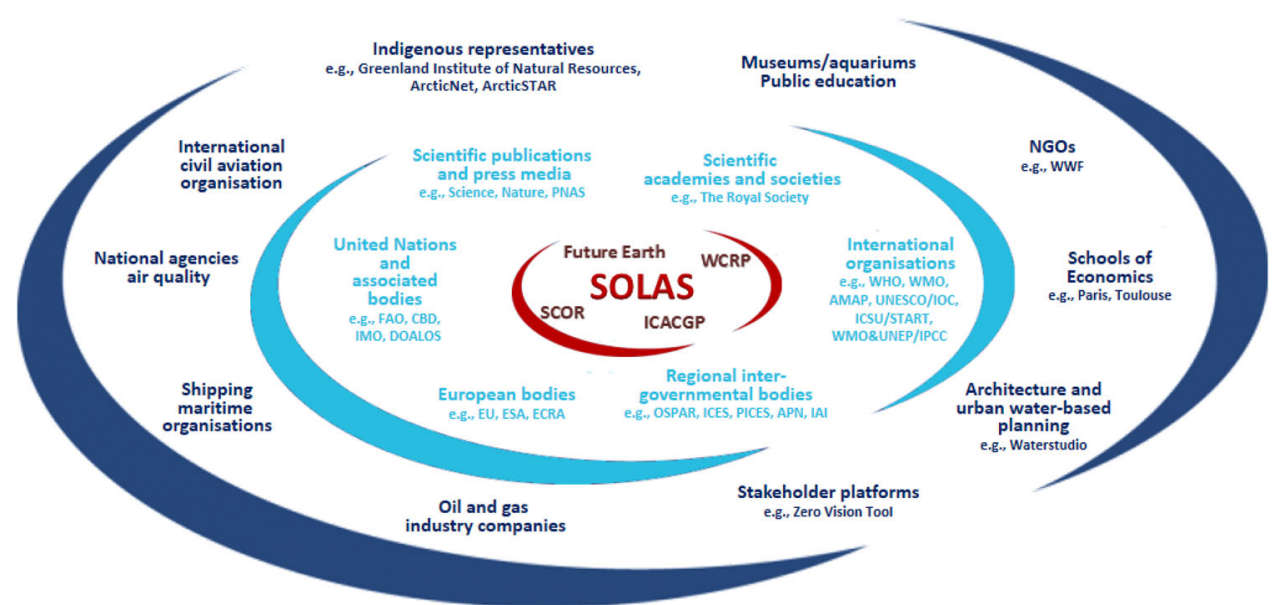

Figure 2. A conceptual diagram with the main stakeholders related to SOLAS science, including examples (Brévière 2016).

existing attempts to forge a specialty area around the sociological study of maritime topics remain limited, because most of the theoretical work remains rooted in Central Europe, with little connection to other parts of the world (for instance, Canada and China) where empirical, sociologically-relevant maritime research has a stronger presence (Hannigan 2017). Nevertheless, successful efforts are being made to address this research deficiency within marine science, with evidence that interdisciplinary approaches are beneficial for all researchers involved. For example, Watson et al. (2016) brought socio-economists and natural marine scientists together to explore the ecosystem service of waste remediation in the marine environment, resulting in the provision of operational guidance on the long-term sustainable use of this process. Fernandes et al. (2017) quantified how the ecological impact of climate change on commercially important marine bivalves could create a cascade of negative economic effects on the fishing industry and its associated revenue and employment.

During the first ten years of the SOLAS, significant gains in knowledge were achieved by scientists in the community and in Earth system science in general (Brévière et al. 2015). SOLAS contributes critical scientific information to the quantification of three of the nine planetary boundaries, which have been proposed to define a 'safe operating space for humanity' (Rockström et al. 2009; Steffen et al. 2015): climate change, biogeochemical flows and ocean acidification. Within these Earth system scale challenges faced by humanity, the program (Figure 1) is poised to provide a scientific basis for sustainable policy-making. The first SOLAS policy-related interactions dealt with oceanic iron fertilization and ocean acidification. For both topics, SOLAS scientists participated in published summaries for policy makers (Wallace et al. 2010; IGBP, IOC, and SCOR 2013). These examples highlight that a coordinated research design from the outset is required to achieve an interdisciplinary approach, successfully bridging the gaps between marine scientists, policy makers and practitioners (Weichselgartner and Marandino 2012; Turner, Bhatta et al. 2017). Thus, the goal for future SOLAS research is to develop research questions in order to co-design future projects related to the SOLAS Science and Society initiative (Figure 2). 


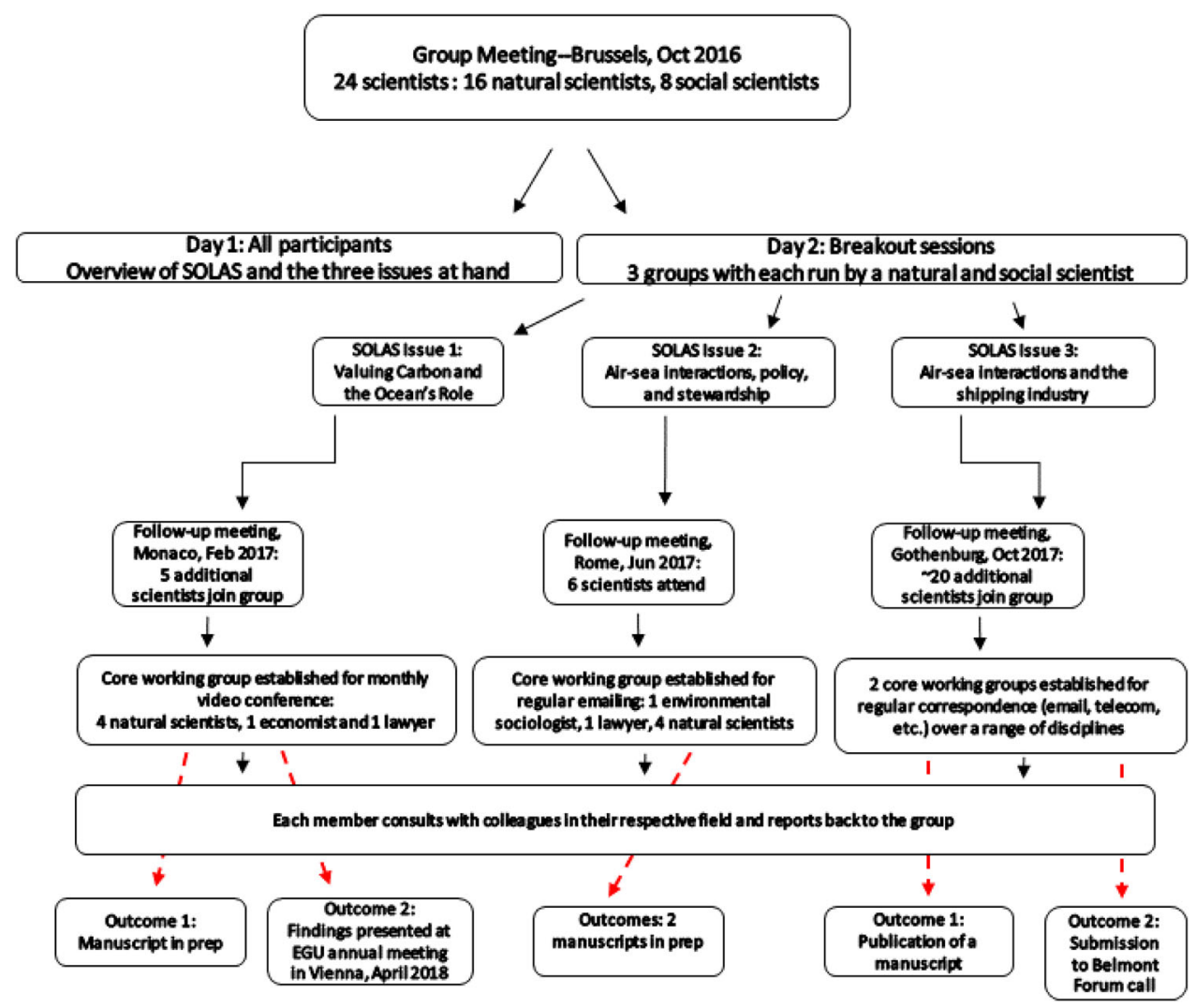

Figure 3. Flowchart illustrating the SOLAS Science and Society initiative process.

The aim of this paper is to illustrate how the SOLAS community plans to address the need for inter- and transdisciplinary research for the ocean-atmosphere system, which is directly in line with the Ocean KAN that SOLAS "must generate knowledge that decision-makers need to preserve and enhance the health and value of the ocean".

\section{Method}

From a broader perspective, there are two possible frameworks for inter- and transdisciplinary SOLAS research: 1) interaction between natural and social science, 2) interaction between science and society. Here the goal was to first focus on the interactions between natural and social science, with the intention to move toward an integration of science and society. Small working groups, comprising experts from different disciplines in both the natural and social sciences, met in person to tackle three predetermined pressing environmental issues (Figure 3). A grassroots effort was made to identify key, as well as developing, links between SOLAS science and the social sciences, and to meet the growing need of bridging the natural and social science gap. The working groups were balanced in terms of both natural and social scientists, each led by one natural and one social scientist. The three issues are: the economics of ocean carbon storage; policy across the air-sea interface and the impact of shipping on air-sea interactions. The structure of the collaborative initiative entailed an initial meeting in October 2016, 
Table 1. Topics and outcomes from the SOLAS Science and Society approach to interdisciplinary research.

\begin{tabular}{|c|c|c|c|}
\hline Topic & Disciplines involved & $\begin{array}{l}\text { Key interdisciplinary } \\
\text { research questions arising }\end{array}$ & $\begin{array}{c}\text { Anticipated future } \\
\text { outcomes of better } \\
\text { interdisciplinary working }\end{array}$ \\
\hline \multirow[t]{3}{*}{$\begin{array}{l}\text { Valuing carbon and the } \\
\text { ocean's role }\end{array}$} & \multirow{3}{*}{$\begin{array}{l}\text { Environmental economics, } \\
\text { ocean carbon and } \\
\text { nutrient biogeochemistry, } \\
\text { air-sea gas exchange, } \\
\text { marine ecosystem } \\
\text { services, marine } \\
\text { biogeochemistry }\end{array}$} & What carbon is 'valuable'? & $\begin{array}{l}\text { A marine and coastal } \\
\text { carbon valuation system } \\
\text { grounded in } \\
\text { biogeochemistry }\end{array}$ \\
\hline & & $\begin{array}{l}\text { How to attribute marine } \\
\text { carbon storage to nation } \\
\text { states for carbon credits? }\end{array}$ & $\begin{array}{l}\text { A legal framework with } \\
\text { natural science } \\
\text { underpinning to support } \\
\text { states in positive action } \\
\text { to protect or enhance } \\
\text { marine carbon stocks }\end{array}$ \\
\hline & & $\begin{array}{l}\text { How to account for } \\
\text { timescales of } \\
\text { carbon storage? }\end{array}$ & $\begin{array}{l}\text { New economic approaches } \\
\text { to marine and coastal } \\
\text { carbon sequestration } \\
\text { valuation based on } \\
\text { biogeochemical } \\
\text { knowledge }\end{array}$ \\
\hline \multirow[t]{3}{*}{$\begin{array}{l}\text { Air-sea interaction, policy } \\
\text { and stewardship }\end{array}$} & \multirow{3}{*}{$\begin{array}{l}\text { Biogeochemical } \\
\text { oceanography, } \\
\text { atmospheric chemistry, } \\
\text { environmental sociology, } \\
\text { ocean surface physics, } \\
\text { international law of the } \\
\text { sea, ocean-atmosphere } \\
\text { interactions }\end{array}$} & $\begin{array}{l}\text { Is the interaction between } \\
\text { the lower atmosphere } \\
\text { and the upper layer of } \\
\text { the ocean sufficiently } \\
\text { addressed in governance? }\end{array}$ & $\begin{array}{l}\text { More comprehensive } \\
\text { governance that } \\
\text { encompasses all impacts } \\
\text { to coupled air- } \\
\text { sea system }\end{array}$ \\
\hline & & $\begin{array}{l}\text { How are air-sea interactions } \\
\text { established as important } \\
\text { without overstating } \\
\text { the effect? }\end{array}$ & $\begin{array}{l}\text { Interdisciplinary assessment } \\
\text { of the significance of } \\
\text { air-sea interaction in } \\
\text { regulation, either } \\
\text { implicitly or explicitly }\end{array}$ \\
\hline & & $\begin{array}{l}\text { Are there cultural/national } \\
\text { differences in how to } \\
\text { effectively promote long- } \\
\text { lasting stewardship of } \\
\text { the open ocean? }\end{array}$ & $\begin{array}{l}\text { Culturally specific public } \\
\text { awareness campaigns } \\
\text { about the open ocean } \\
\text { grounded in } \\
\text { interdisciplinary science }\end{array}$ \\
\hline \multirow[t]{3}{*}{$\begin{array}{l}\text { Air-sea interactions and } \\
\text { the shipping industry }\end{array}$} & \multirow{3}{*}{$\begin{array}{l}\text { Ecological economics, } \\
\text { microbial and marine } \\
\text { trace gas } \\
\text { biogeochemistry, } \\
\text { international law of the } \\
\text { sea and the } \\
\text { environment, boundary } \\
\text { layer meteorology, } \\
\text { atmospheric chemistry } \\
\text { and physics, innovative } \\
\text { shipping, fluid dynamics }\end{array}$} & $\begin{array}{l}\text { What is the value of clean } \\
\text { air and water, especially } \\
\text { in coastal and pristine } \\
\text { environments? }\end{array}$ & $\begin{array}{l}\text { Interdisciplinary evaluation } \\
\text { of the effects and risks } \\
\text { of shipping emissions to } \\
\text { the atmosphere and } \\
\text { the ocean }\end{array}$ \\
\hline & & $\begin{array}{l}\text { Is this applicable as } \\
\text { sustainability and circular } \\
\text { economy for marine } \\
\text { ecosystem services? }\end{array}$ & $\begin{array}{l}\text { Actions to support the } \\
\text { move to a more circular } \\
\text { economy can motivate } \\
\text { the shipping industry to } \\
\text { develop sustainable/ } \\
\text { clean technologies }\end{array}$ \\
\hline & & $\begin{array}{l}\text { How can future shipping be } \\
\text { sustainable? }\end{array}$ & $\begin{array}{l}\text { International policy } \\
\text { dialogues for global } \\
\text { emission control, } \\
\text { improved standards, } \\
\text { technologies and } \\
\text { monitoring guidelines } \\
\text { for application of } \\
\text { exhaust gas } \\
\text { cleaning systems. }\end{array}$ \\
\hline
\end{tabular}

in which 24 natural and social scientists met in Brussels for a two-day workshop. The first day consisted of presentations on the three topics, then on the second day the breakout groups addressed each of the three topics.

From 2017 to the present day, follow-up meetings for each topic are held, and participation has been extended to a wider group who were suggested and selected by 
members of the initial breakout groups. These meetings mostly consist of regular teleconferences (bi-weekly to monthly, on average), in which tasks were assigned, and collaborative efforts were made toward manuscripts and funding proposals. Additionally, members presented the groups' findings at research conferences. The specific aim was to have at least three concrete outcomes related to these topics in the coming years, such as papers in peer-reviewed journals and research proposals, which are discussed in more detail below.

\section{Targeted research topics}

Here the outcomes of the three targeted research topics are summarized, focusing on the interdisciplinary issues identified in the initial workshop. Some of these issues have already been identified and discussed in the literature, while others are novel. All of them present key opportunities for future work to better understand the challenges associated with translating natural science into societal impact (Table 1).

\section{Valuing carbon in the ocean}

\section{Background}

The ocean system takes up carbon from the atmosphere through both physical and biological mechanisms, currently taking up a similar proportion of anthropogenic $\mathrm{CO}_{2}$ emissions as the land surface (e.g., Heinze et al. 2015). The physical uptake of carbon dioxide $\left(\mathrm{CO}_{2}\right)$ by the oceans has increased in response to anthropogenic carbon input to the atmosphere, but this has potentially negative consequences through ocean acidification, which may affect uptake of $\mathrm{CO}_{2}$ by marine organisms as well as other harmful effects. There have been extensive ongoing discussions in the scientific community about roles and vulnerabilities of the physical, biological and microbial carbon pumps in regulating $\mathrm{CO}_{2}$ uptake from the atmosphere (Heinze et al. 2015), however the ability to manage these processes and their responses to future climate change and rising $\mathrm{CO}_{2}$ is limited at best. Between these large-scale natural processes and the coastal habitats recognized as valuable Blue Carbon ecosystems lie a broad range of natural processes and potential management options in coastal seas and the open ocean which may offer opportunities to mitigate atmospheric $\mathrm{CO}_{2}$ (e.g., Gattuso et al. 2018).

The term 'Blue Carbon' has typically been used to describe the carbon storage services associated with coastal and intertidal wetlands and sub-tidal near-shore vegetated ecosystems: predominantly salt marsh, mangrove and seagrass (Laffoley and Grimsditch 2009; Pendleton et al. 2012). Other systems (e.g., kelp, phytoplankton, water column carbon) have also been considered in some studies (Burrows et al. 2014) and discounted as not valuable for management and conservation strategies and, therefore, not thought to be useful carbon stores by others (e.g., Howard et al. 2017). The above-mentioned studies, along with numerous others on each side of this debate, discuss the issue of biogeochemical carbon accounting vs. ecological valuation for conservation and, thus, come to different conclusions. To make informed assessments of the potential 'value' of different components of the ocean carbon cycle, the input of experts in ocean 


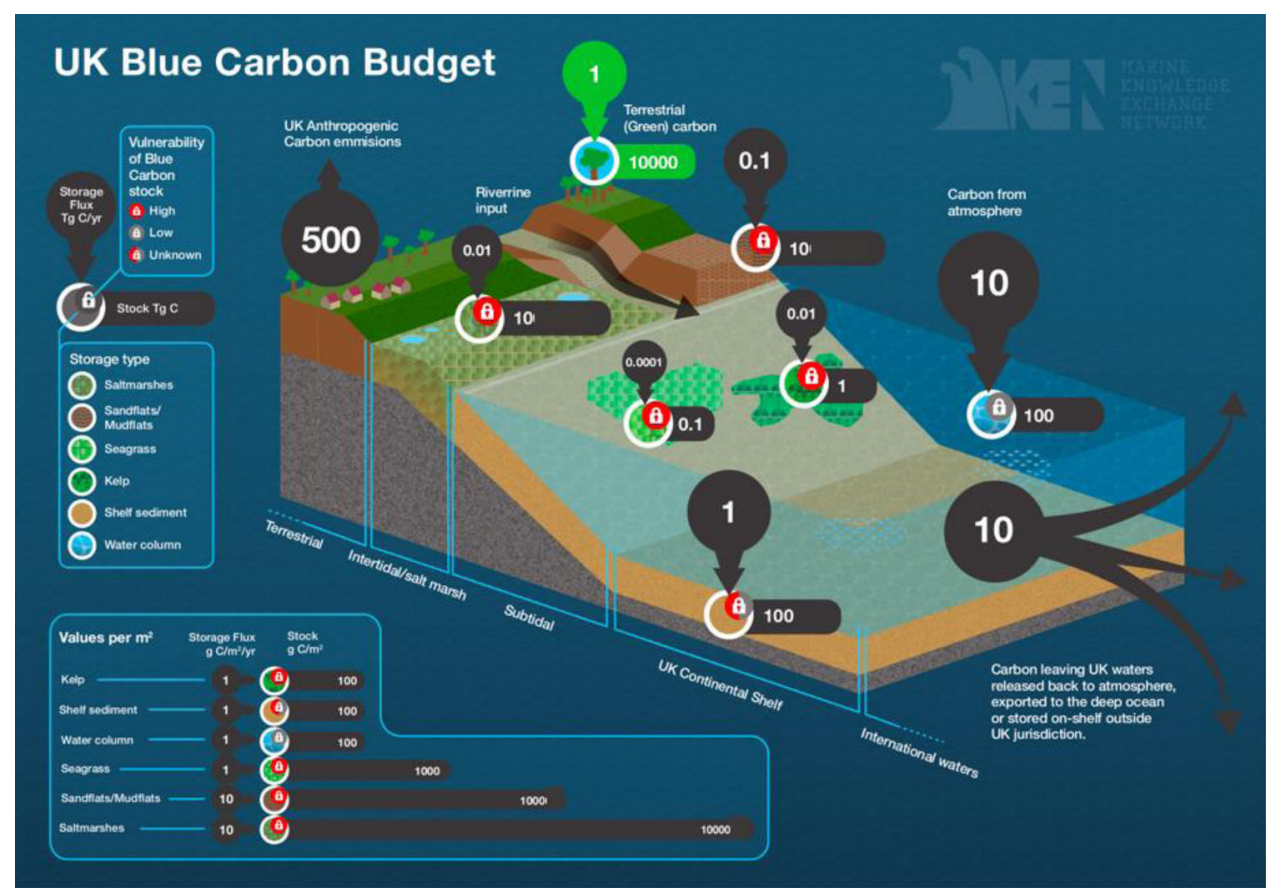

Figure 4. Example assessment of 'Marine and Coastal Carbon Sequestration' (MCCS) developed by the Marine Knowledge Exchange Network (Johnson et al., 2020) for the UK Shelf Sea Biogeochemistry Project. Standing carbon stocks and fluxes from the coast to the shelf are pictured together with an indication of their vulnerability. Note that qhatitative data shown here is superceded by the data presented in Legge et al. (2020). Figure provided by the Marine KnowledgeExchange Network (http:// www.uea.ac.uk/mken)

biogeochemistry and Earth system science from the domains of SOLAS and related international research programs (e.g., such as IMBeR, the Integrated Marine Biosphere Research), as well as ecologists and environmental economists, are clearly needed.

\section{Challenges and opportunities}

Fundamentally, what should and should not be considered when investigating Blue Carbon depends on the motivation for counting the carbon stored: whether as a conservation mechanism for important and threatened habitats or as an economic mechanism to unlock additional carbon storage potential in marine systems as a means to mitigate atmospheric $\mathrm{CO}_{2}$ increase (see example in Figure 4). This debate is ongoing in the Blue Carbon community (e.g., Howard et al. 2017; Macreadie et al. 2019). Here that particular debate was bypassed and a broader 'Marine and Coastal Carbon Sequestration' (MCCS) was defined as any carbon stored in the marine realm by processes whose absence would lead eventually to an equivalent quantity of carbon being released to the atmosphere. All MCCS renders ecosystem services to humanity and it is argued that it is crucial to assess its total economic value, because these calculations allow policy makers to know how important this service is in terms of costs and benefits, whether directly manageable or not. It is also important to account for the balance of the associated uptake or emission of other climate-active gases. 
As compared to the terrestrial realm, movement of water throughout the oceans occurs irrespective of geopolitical boundaries (carbon does not stay where it was fixed, unlike, e.g., forest storage where the carbon stays in the trees which fix it for decades or more), thereby presenting unique challenges in attribution and valuation of measures to enhance carbon storage in coastal waters. The open ocean is not considered here, as the processes that can be manipulated/controlled are more limited than in coastal areas. Positive or detrimental effects, whether natural or anthropogenic, might originate in territorial waters of any one nation. Depending on the ocean circulation, such effects might materialize in waters of neighboring states. Furthermore, states bordering upwelling systems, which bring carbon-rich waters from depth, might have large natural effluxes of carbon from their national waters. Such approaches and budgets, as for example pursued by Melaku Canu et al. (2015), who account for the total (natural and management-derived) carbon balance of states bordering the Mediterranean Sea, are potentially highly misleading to decision makers; they conflate carbon storage or emissions as a result of management decisions, with unmanageable, natural emissions. These measures largely attribute and value effects of circulation pattern, rather than active measures to enhance carbon storage, or damaging management approaches that lead to the release of carbon. Active measures are crucial for any international agreements or assessments of carbon storage initiatives, while the Melaku Canu et al. (2015) approach largely describes natural background conditions, which should not be counted as an asset or mismanagement of individual states. Under no circumstances, for example, would it be sensible or reasonable to attribute a cost to the West African states for the natural carbon emissions from the Mauritanian upwelling where carbon-rich deep ocean waters rise to the surface.

One such active measure is the expansion of macroalgal aquaculture, which has been recognized as having great potential to take up excess atmospheric $\mathrm{CO}_{2}$ (e.g., Lehahn, Ingle, and Golberg 2016; Antoine de Ramon et al. 2012), when it is subsequently sequestered. However the ethical, legal and technological barriers to this measure, the need for environmental protection and scientific oversight and the short timescales over which many orders of magnitude expansion would need to occur present enormous challenges (e.g., Buschmann et al. 2017; Duarte et al. 2017). This highlights the need to rapidly increase research into ocean carbon mitigation solutions considering natural and social aspects simultaneously.

A further point to consider is the time scale of carbon storage. The baseline here is the (former) long-term geological storage of fossil fuels in the Earth system, while at the other end are the short-term annual or multi-annual time scales of economic budgeting and valuation or election frequency. From the Earth system perspective, glacial-interglacial or longer timescales matter to ensure long-term stability of the climate. In terms of uptake of anthropogenic $\mathrm{CO}_{2}$ and ocean acidification, ocean turnover timescale matters. Carbon credits, as a "cap and trade" instrument, apply at decadal timescales or even shorter, such as election cycles. They can give a monetary value to the cost of polluting the air in order to reduce the pollution. The underlying, yet unanswered, key question is: what carbon storage time scale is applied to or described for MCCS stocks?

\section{Outcome}

A series of key questions and knowledge gaps around MCCS were identified (Table 1). These range from the lack of consensus on its definition and purpose to identification 
of the need to apply Earth-system scale understanding of the ocean carbon cycle if the concept of MCCS is to be used to incentivize positive action, particularly in marine systems beyond those at or very close to the coast. Currently, the group consisting of an economist, a lawyer, three marine carbon specialists, and one air-sea interaction expert is drafting a submission which investigates the opportunities and vulnerabilities of coastal to open ocean carbon storage reservoirs (Figure 3).

\section{Air-sea interaction, policy, and stewardship}

\section{Background}

A pressing question related to the open ocean is if there are cultural/national differences in how to effectively promote long-lasting stewardship of the high seas. This theme could likely lead to a project studying global attitudes toward the open ocean and the development of methods to promote long-lasting stewardship (including the identification of what methods work and for whom). A sensible start for marine stewardship might be the creation of a stronger awareness among the transnational public, rather than with a set of separate, national policy initiatives. However, because most people do not have direct experience of the high seas, they often rely on representations fraught with sensationalism and ambiguity of an outlaw ocean that is both a source of wealth and danger (Langewiesche 2004). The fact that perspectives on the ocean are subject to change and are often culture-specific complicates this. To communicate effectively and engage the population, crossing national and cultural boundaries must be understood. In other words, the sea must be thought of not only as a medium but also as a social space, which is not merely 'used by society' but rather represents 'a space of society' that is connected and experienced in specific ways by specific people (Lambert, Martins, and Ogborn 2006).

These questions regarding stewardship deal only with the marine environment. Yet the very existence of international projects such as SOLAS shows that, from the perspective of natural sciences, the boundary between the ocean and the atmosphere cannot be clearly drawn. There is much interaction between the surface of the ocean and the lower part of the atmosphere. The policy perspective, however, tends to make a clear distinction between the ocean and the air directly above it, without much consideration of the interaction between them. Regulatory frameworks for the governance of the ocean on the one hand and the atmosphere on the other reflect this compartmentalization. The international regulatory framework for the ocean bases itself mainly on the 1982 United Nations Convention on the Law of the Sea (LOSC; Rothwell and Stephens 2016). The atmosphere lacks a global, all-encompassing regulatory framework like the LOSC (Sands et al. 2018) since the international rules for the atmosphere developed later than the customary international law of the sea. Regional efforts on long-range transboundary air pollution, with a focus on acid rain, occurred first in the 1970s with the 1979 Convention on Long Range Transboundary Air Pollution (LRTAP). On a global level, first efforts concentrated on the effects of air pollution, with a focus on the depletion of the ozone layer in the 1980s through the 1985 Vienna Convention for the Protection of the Ozone Layer and its 1987 Montreal Protocol. In the next decade, regulation addressed climate change with the 1992 United Nations Framework Convention on Climate Change as a starting point (Gillespie 2006; Sands et al. 2018). 


\section{Challenges}

This study considers whether the biogeochemical interaction between the lower atmosphere and the upper layer of the ocean is addressed in regulations. Regulations might not target this air-sea interface directly - human-made rules cannot govern natural processes - but they do regulate sources of pollution (e.g., atmospheric emissions at the national and regional level) or designated areas in need of a higher protection (e.g., sulfur control areas [SECAs] for ships). The rationale behind this is that the regulation of activities on land or on ships (i.e., the cause of atmospheric pollution) is mostly a sovereign duty of states - whether land-locked, coastal or flag states - which is exercised in line with their national policies. There is nevertheless a general obligation under the LOSC for states to prevent, reduce and control pollution of the marine environment from or through the atmosphere.

Air-sea exchange is one of the primary processes in the biogeochemical cycling of many chemicals but rarely is it the defining feature that requires regulation. The role of the atmosphere-ocean interface in the cycling of mercury, a highly toxic substance, serves as an example. The dominant source of mercury to the ocean is atmospheric deposition and approximately $80 \%$ of this is subsequently re-emitted to the atmosphere (Driscoll et al. 2013). The use, trade and disposal of mercury is now highly regulated, including via the 2013 United Nations Minamata Convention, but processes of air-sea exchange are not explicitly addressed in policy or regulations, beyond recommendations for improving or expanding research and monitoring (UNEP 2013). Similarly, air-sea exchange has been a significant process influencing the biogeochemical cycling of persistent organic pollutants (POPs), such as polychlorinated biphenyls and organochlorine pesticides (Wöhrnschimmel et al. 2012). In this case, again, regulations or policy addressing air-sea exchange are not explicitly addressed in POP management policies (e.g., the 1998 Aarhus POPs Protocol to the LRTAP Convention).

One instance of where air-sea exchange can be considered to have been explicitly included in environmental policy is the regulation of ocean iron fertilization. This process has been promoted as a carbon mitigation scheme whereby iron is added to ocean surface waters to promote phytoplankton production and subsequent draw down of $\mathrm{CO}_{2}$ from the atmosphere. Thus, carbon is sequestered by incorporation in plankton and the ensuing removal via sedimentation and long-term storage in ocean sediments (Wallace et al. 2010). However, international efforts have been made to restrict iron fertilization activities to small-scale scientific research through interpretations of the Convention on Biological Diversity and amendments to the London (Dumping) Convention following concerns raised over the ethical, legal and scientific merits of this form of climate intervention (Strong et al. 2009). However, the overall policy aim is to protect the ocean, not the atmosphere.

All in all, direct consideration of ocean-atmosphere exchange appears to be limited in current international regulations. Thus, a key follow-up question on air-sea policy is: should the air-sea interface be considered in regulations for the implications of the physical and biogeochemical processes in which it is involved (Steinacher, Joos, and Stocker 2013)? If the answer to this second key question is positive, how do oceanatmosphere interactions become established as a topic that policy-makers are able to address in regulations? Experience within the SOLAS community in advising policy makers, for example in the field of climate mitigation, make it well-placed to scrutinize the potential value of such consideration in the future. 


\section{Outcome}

A multidisciplinary group is now working on the identified key questions in promoting lasting open ocean stewardship and on policy across the ocean-atmosphere interface (Table 1, Figure 3). This activity seeks to highlight the main gaps in understanding to support future research proposals. The work on policy across the ocean-atmosphere interface aims at highlighting the potential need for an explicit integration of this interface in policy-making through an analysis of relevant international legislation, where this would improve the policies' effectiveness through a more holistic approach. So far, it appears that policy-makers hardly explicitly consider this interface. A session to be included in the Sustainability Research + Innovation Congress 2020 in Brisbane, Australia proposes to explore these gaps in relation to policy across the air-sea interface and addresses discrepancies between ocean-atmosphere science and policy. The session deals with the influence of the atmosphere on the ocean and/or feedbacks from ocean to atmosphere that could or should have a direct or indirect impact on marine policy, any social science perspectives that relate to the air-sea interface, and topics that address the integration of ocean and atmosphere regulatory frameworks and governance.

\section{Air-sea interactions and the shipping industry}

\section{Background}

During the last decades, shipping traffic has grown faster than the world economy (UNCTAD 2017) and this trend is expected to continue in the future. There is growing concern about the marine environmental impacts of shipping traffic, from both operational and accidental discharges of pollutants (oil residues, bilges, garbage, ballast water, air pollutants), which may negatively affect the marine environment at scales from species-level to broader effects on ecosystem services. To combat anthropogenic climate change, strict emission controls of greenhouse gases and pollutants in maritime transport are needed and (will be) implemented in a stepwise manner by flag states and port states (see next paragraph for details). Within international law, the ability of coastal states to impose and enforce their own environmental and navigation regulations on foreign ships is limited. Instead, states use international conventions established through the International Maritime Organization (IMO) in which flag states have a dominant position. Increased interaction between natural scientists and social scientists might lead to progress in developing new international conventions concerned with green shipping, clean scrapping of ships and improved port management.

Approximately $80 \%$ of fuel used by the global shipping fleet in 2010 was low-cost, heavy fuel oil (HFO) (Smith et al. 2015). Today, commercial shipping still mainly uses HFO outside specially designated emission control areas (such as SECAs and in port areas), emitting significant amounts of sulfur, nitrogen, metals, hydrocarbons, organic compounds and aerosols to the atmosphere during combustion (Eyring et al. 2005; Turner, Hassellöv et al. 2017). As some of these compounds have a limited residence time in the atmosphere, they are deposited relatively close to the source and dissolve or suspend in the surface ocean. In 2015, the IMO adopted a reduction in the maximum ship sulfur emission (from $1 \%$ to $0.1 \%$ of fuel mass) in the SECAs of North Europe and North America (included in the International Convention for the Prevention of 
Pollution from Ships-MARPOL-Annex VI) while the EU Sulfur Directive EU 2016/802 applies the same objective in the ports of EU-member states outside SECAs. From January 2020, the IMO requires all shipping in international waters to reduce sulfur emissions from $3.5 \%$ to $0.5 \%$ of fuel mass. Some states, such as China, require an Scontent of $0.5 \%$ instead of $3.5 \%$ for ships in their main ports and coastal waters, for example in Shenzhen Port Area, Hong Kong harbor, ports in the Yangtze River Delta, the Pearl River Delta and the Bohai Sea. Several sulfur emission reduction technologies exist for achieving the international emission limits. Open-loop (and to some extent closed-loop) exhaust gas cleaning systems ('scrubbers') are increasingly used to comply with stricter fuel emission regulations, especially since the new regulations started in 2020. The increased costs associated with high-quality, low-sulfur content fuel oil have shaped scrubber technology to be an attractive and viable alternative especially for larger vessels that still use HFO (Lindstad and Eskeland 2016). However, little is known about the chemical composition of the scrubber effluent and its ecological consequences for marine life and biogeochemical processes (Endres et al. 2018). Ecotoxicological studies on marine pollutants (e.g., metals and polycyclic aromatic hydrocarbons) imply that scrubber wash water could have a harmful effect on marine organisms and marine ecosystems (Ivanina and Sokolova 2015). Scrubber technology focuses mainly on the removal of sulfur from the exhaust. Other pollutants, such as fine particulate matter, heavy metals and organic compounds are not reduced to the same extent.

\section{Challenge}

Although the use of new technologies, such as scrubbers, benefits the environment by significantly reducing ship emissions to the atmosphere, their use may lead to other, as yet unascertained and unquantified, negative impacts on the marine environment (Endres et al. 2018). In the long term perspective, it is likely that long-distance shipping will replace fuel oil by cleaner alternatives, such as liquefied natural gas (LNG) or methanol in order to comply with the IMO strategy on reduction of greenhouse gas emissions by $70 \%$ by 2050 compared to 2008 . The consequences of increasing LNG or methanol use needs to be investigated, especially as both are known to leak methane to the atmosphere, which is a stronger greenhouse gas than carbon dioxide. For these topics, it is important to collaborate with industrial partners in order to find economically viable solutions that do not create additional environmental hazards.

Ship emission models such as STEAM3 (Jalkanen et al. 2009; Jalkanen et al. 2012; Johansson, Jalkanen, and Kukkonen 2017), combining ship traffic data from Automatic Identification System with a technical database consisting of ship emission factors and other characteristics, allow modeling of global ship emissions. The ability to more accurately forecast the release of greenhouse gases and pollutants using such models is a potentially powerful tool for ensuring compliance with legislation and regulations and to assess the future environmental impact of maritime transport. However, due to its complex nature, this requires further modeling efforts, validation by in-situ measurements of emissions on-board and in the surface ocean, and the integration of future socio-economic developments, such as future regulations on fuel types and ship emissions. 


\section{Outcome}

Several interdisciplinary research priorities have been identified within this initiative, which will help develop an environmentally sustainable shipping industry, and avoid the transformation of one type of pollution into another (Endres et al. 2018 - a direct result of the SOLAS process, Table 1, Figure 3). Among these, more attention should be paid to improve implementation, compliance, and enforcement of adequate environmental standards by flag states (the jurisdiction under which a vessel falls) and port state control. In addition, experimental studies are crucial to increase understanding of the ecological and biogeochemical effects of ship-sourced pollution (e.g., scrubber wash water discharges). To better forecast the effects of ship emissions and future projections of scrubber technology usage, atmospheric and ocean model studies need to be improved with high resolution monitoring data of ship traffic and pollutants in water and air, coupled with socio-economic models. To this end, a Collaborative Research Action on Transdisciplinary Research for Ocean Sustainability proposal (ShipTRASE, call initiated by the Belmont Forum and JPI Oceans) has been granted to an international consortium of natural scientists, engineers, lawyers, and economists to investigate short-term (with scrubber technology) and long-term (LNG) ship emissions on air-sea interactions and subsequent feedbacks with policy and the economy. This proposal is direct outcome of the SOLAS initiative described here.

\section{Outlook/suggestions for future implementation}

Since the launch of Future Earth at the Planet Under Pressure meeting in London, 2012, the need for increased integration of the natural and social sciences has risen to even more prominence. Future Earth developed the Ocean KAN to support this integration, which underscores the call for solution-oriented research. This paper provides a look at how the SOLAS community would like to address this research need and outlines the initial steps that must be taken. This publication is intended to act as a foundation that enables the air-sea interaction community to confront relevant issues at the natural and social science interface. Through this process we have determined that our overarching goal is to galvanize the participation of non-natural scientists over a range of disciplines, from economy to law to sociology and environmental psychology, within the SOLAS network We have identified the following challenges: 1) achieving effective communication, which we can tackle by changing the lack of a common language between the disciplines and the frequent use of jargon; 2) the use of different methodologies, which can be mitigated by forging close relationships across disciplines in order to obtain insight into the various research styles; 3) obtaining the appropriate balance between curiosity-driven fundamental research and the perceived need to co-design science jointly as a product of scientists and stakeholders. This last concern is often expressed by scientists stating that a co-design approach might be considered too 'topdown' and that the added scientific value may not always be evident. In addition, it might be difficult to convince some traditional fundamental research funding agencies to allow for appropriate financial schemes and time frames to accommodate codesigned research, and the complementing co-produced outcomes, to serve both science and stakeholders. 
The wider implementation of the collaborative structure discussed above is proposed. Topics that can be considered include harmful algal blooms and macroalgae farming. The outcome of these efforts was a more holistic and comprehensive approach to pressing and globally relevant issues that is often achieved with more traditional cursory collaborations between the natural and social sciences. The success of this collaborative model for the three working groups suggests that this approach should be more frequently adopted in interdisciplinary research between natural and social scientists, especially in addressing SOLAS issues. Future endeavors could entail the expansion of existing working groups such as those of the SCOR to include social scientists, economists and lawyers. It could also mean collaborative sessions at major annual research conferences that include members of both the natural and social science communities. Furthermore, researchers should lobby their academic department to partner with other departments at their institution. Examples of such collaborations include the Martin School and Environmental Change Institute at the University of Oxford, the Global Systems Institute at Exeter University, and the Grantham Institute at Imperial College, which encourage interdisciplinary research. Additionally, the Canadian ocean acidification research program (COARP) was jointly led by natural scientists and economists from Dalhousie University. Finally, existing programs should strive to achieve better inclusivity and appropriate participation amongst disciplines. For instance, the International Panel for Climate Change (IPCC) assessment report (IPCC 2014) was comprised of multiple working groups, but none of them had significant representation from the social sciences. Even Working Group II on Impacts, Adaptation and Vulnerability, which aimed to 'assess the vulnerability of socioeconomic systems to climate change', did not have economists serving as co- or vice chairs. Considering this, it is recommended that enhanced efforts are made to ensure that existing organizational structures become more equitable in terms of representation from the natural and social sciences.

In the transition to interfacing directly with society, we see that certain changes to our method could be beneficial. For example, a better definition of the issues and key messages could be a helpful starting point for framing research ideas. Tools such as the Responsible Research and Innovation website (www.rri-tools.eu) can be an effective starting point for future discussions related to SOLAS science and society. There is a clear need to find compromises to overcome perceived differences in the goals, timelines and resource needs between the social and natural science communities, and stakeholders. Different perspectives must be identified and collated in order to respond to challenges within the marine system, yet the purpose of the integration for different collaborative projects may not always be the same (Frodeman, Klein, and Mitchum 2012). Furthermore, starting from a natural science perspective may not be the most effective way to identify overlaps between social and natural science disciplines. A better starting point might be scientific topics that are more immediately connected to public rights and responsibilities. These may then lead into SOLAS research specialities. Because targets and goals can differ between scientific communities and the wider population, a systematic understanding of those different perspectives will help to bridge that gap. The inclusion of other disciplines would allow us to consider the objectives and the moral dilemmas from the perspective of different actors, determine the arguments for and against different solutions, and pinpoint how to find the best outcomes, including 
those for the oceans. The work presented here can lead the way to future co-designed research on additional topics fitting to the SOLAS mission and to its sponsors, such as Future Earth, in general.

\section{Acknowledgements}

The authors wish to thank the SOLAS International Project Office and Scientific Steering Committee for the funding/encouragement to hold this workshop and the Kooperationsstelle EU der Wissenschaftsorganisationen (KOWI) for hosting us in Brussels.

\section{Funding}

Erik van Doorn and Sonja Endres acknowledge the support of the Cluster of Excellence 'The Future Ocean' in Kiel, Germany. Monica Mårtensson acknowledges the Swedish Research Council Formas, contract no. 2011-1007. Helmuth Thomas acknowledges support by the German Academic Exchange Service (DAAD, MOPGA-GRI, \#57429828) supported by funds of the German Federal Ministry of Education and Research (BMBF).

\section{References}

Antoine de Ramon, N. Y., D. P. Chynoweth, M. E. Capron, J. R. Stewart, and M. A. Hasan. 2012. Negative carbon via ocean afforestation. Process Safety and Environmental Protection 90 (6):467-74. doi: 10.1016/j.psep.2012.10.008.

Bailey, M., B. Favaro, S. P. Otto, A. Charles, R. Devillers, A. Metaxas, P. Tyedmers, N. C. Ban, T. Mason, C. Hoover, et al. 2016. Canada at a crossroad: The imperative for realigning ocean policy with ocean science. Marine Policy 63:53-60. doi: 10.1016/j.marpol.2015.10.002.

Brévière, E. 2016. SOLAS 2015-2025: Science plan and organisation. SOLAS International Project Office, GEOMAR Helmholtz Centre for Ocean Research Kiel, Kiel, Germany.

Brévière, E. H. G., D. C. E. Bakker, H. W. Bange, T. S. Bates, T. G. Bell, P. W. Boyd, R. A. Duce, V. Garçon, M. T. Johnson, C. S. Law, et al. 2015. Surface ocean-lower atmosphere study: Scientific synthesis and contribution to Earth system science. Anthropocene 12:54-68. doi: 10. 1016/j.ancene.2015.11.001.

Brink, M., M. Hengeveld Geerten, and H. Tobi. 2020. Interdisciplinary measurement: A systematic review of the case of sustainability. Ecological Indicators 112:106145. doi: 10.1016/j.ecolind. 2020.106145.

Burrows, M. T., N. A. Kamenos, D. J. Hughes, H. Stahl, J. A. Howe, et al. 2014. Assessment of carbon budgets and potential blue carbon stores in Scotland's coastal and marine environment. Scottish Natural Heritage Commissioned Report No. 761, United Kingdom.

Buschmann, A. H., C. Camus, J. Infante, A. Neori, Á. Israel, M. C. Hernández-González, S. V. Pereda, J. L. Gomez-Pinchetti, A. Golberg, N. Tadmor-Shalev, et al. 2017. Seaweed production: Overview of the global state of exploitation, farming and emerging research activity. European Journal of Phycology 52 (4):391-406. doi: 10.1080/09670262.2017.1365175.

Chernilo, D. 2007. A social theory of the nation state. The political forms of modernity beyond methodological nationalism. Routledge: London.

Cocco, E. 2013. Theoretical implications of maritime sociology. Annuals of Maritime Sociology XXII:5-18.

Driscoll, C. T., R. P. Mason, H. M. Chan, D. J. Jacob, and N. Pirrone. 2013. Mercury as a global pollutant: Sources, pathways, and effects. Environmental Science \& Technology 47 (10):4967-83. doi: $10.1021 /$ es305071v.

Duarte, C. M., J. Wu, X. Xiao, A. Bruhn, and D. Krause-Jensen. 2017. Can seaweed farming play a role in climate change mitigation and adaptation? Frontiers in Marine Science 4:100. doi: 10. $3389 /$ fmars.2017.00100. 
Endres, S., F. Maes, F. Hopkins, K. Houghton, E. M. Mårtensson, J. Oeffner, B. Quack, P. Singh, and D. Turner. 2018. A new perspective at the ship-air-sea-interface: The environmental impacts of exhaust gas scrubber discharge. Frontiers in Marine Science 5: 139. doi: 10.3389/ fmars.2018.00139.

Eyring, V., H. W. Köhler, J. van Aardenne, and A. Lauer. 2005. Emissions from international shipping: 1. The last 50 years. Journal of Geophysical Research 110 (D17):D17305. doi: 10.1029/ 2004JD005619.

Fernandes, J. A., E. Papathanasopoulou, C. Hattam, A. M. Queirós, W. W. W. L. Cheung, A. Yool, Y. Artioli, E. C. Pope, K. J. Flynn, G. Merino, et al. 2017. Estimating the ecological, economic and social impacts of ocean acidification and warming on UK fisheries. Fish and Fisheries 18 (3):389-411. doi: 10.1111/faf.12183.

Fischer, A. R. H., H. Tobi, and A. Ronteltap. 2011. When natural met social: A review of collaboration between the natural and social sciences. Interdisciplinary Science Reviews 36 (4):341-58. doi: 10.1179/030801811X13160755918688.

Frodeman, R., J.-T. Klein, and C. Mitchum. 2012. The Oxford handbook of interdisciplinarity. New York: Oxford University Press.

Gattuso, J.-P., A. K. Magnan, L. Bopp, W. W. L. Cheung, C. M. Duarte, J. Hinkel, E. Mcleod, F. Micheli, A. Oschlies, P. Williamson, et al. 2018. Ocean solutions to address climate change and its effects on marine ecosystems. Frontiers in Marine Science 5:337. doi: 10.3389/fmars.2018. 00337.

Gillespie, A. 2006. Climate change, ozone depletion and air pollution: Legal commentaries within the context of science and policy. Leiden \& Boston: Martinus Nijhoff Publishers.

Glavovic, B. C., K. Limburg, K.-K. Liu, K.-C. Emeis, H. Thomas, H. Kremer, B. Avril, J. Zhang, M. R. Mulholland, M. Glaser, et al. 2015. Living on the margin in the anthropocene: Engagement arenas for sustainability research and action at the ocean-land interface. Current Opinion in Environmental Sustainability 14:232-8. doi: 10.1016/j.cosust.2015.06.003.

Hannigan, J. 2017. Toward a sociology of oceans. Canadian Review of Sociology/Revue Canadienne de Sociologie 54 (1):8-27. doi: 10.1111/cars.12136.

Heinze, C., S. Meyer, N. Goris, L. Anderson, R. Steinfeldt, N. Chang, C. Le Quéré, and D. C. E. Bakker. 2015. The ocean carbon sink - impacts, vulnerabilities and challenges. Earth System Dynamics 6 (1):327-58. doi: 10.5194/esd-6-327-2015.

Helmreich, S. 2009. Alien ocean: Anthropological voyages in microbial sea. Berkeley: University of California Press.

Howard, J., A. Sutton-Grier, D. Herr, J. Kleypas, E. Landis, E. Mcleod, E. Pidgeon, and S. Simpson. 2017. Clarifying the role of coastal and marine systems in climate mitigation. Frontiers in Ecology and the Environment 15 (1):42-50. doi: 10.1002/fee.1451.

IGBP, IOC, and SCOR. 2013. Ocean acidification summary for policymakers - Third Symposium on the Ocean in a High- $\mathrm{CO}_{2}$ World. International Geosphere-Biosphere Programme, Stockholm, Sweden.

IPCC. 2014. Climate change 2014: Synthesis Report. Contribution of Working Groups I, II and III to the Fifth Assessment Report of the Intergovernmental Panel on Climate Change, eds. R.K. Pachauri and L.A. Meyer, 151 pp. Geneva, Switzerland: IPCC.

Ivanina, A. V., and I. M. Sokolova. 2015. Interactive effects of metal pollution and ocean acidification on physiology of marine organisms. Current Zoology 61 (4):653-68. doi: 10.1093/czoolo/ 61.4.653.

Jalkanen, J.-P., L. Johansson, J. Kukkonen, A. Brink, J. Kalli, and T. Stipa. 2012. Extension of an assessment model of ship traffic exhaust emissions for particulate matter and carbon monoxide. Atmospheric Chemistry and Physics 12 (5):2641-59. doi: 10.5194/acp-12-2641-2012.

Jalkanen, J.-P., A. Brink, J. Kalli, H. Pettersson, J. Kukkonen, and T. Stipa. 2009. A modelling system for the exhaust emissions of marine traffic and its application in the Baltic Sea area. Atmospheric Chemistry and Physics 9 (23):9209-23. doi: 10.5194/acp-9-9209-2009.

Johansson, L., J.-P. Jalkanen, and J. Kukkonen. 2017. Global assessment of shipping emissions in 2015 on a high spatial and temporal resolution. Atmospheric Environment 167:403-15. doi: 10. 1016/j.atmosenv.2017.08.042. 
Johnson, M. T., G. A. Bayliss Brown, V. Danino, S. Day, I. Dunnett, J. Forster, L. J. Johnson, I. Lorenzoni, K. Kennedy, G. Malin, et al. 2020. The Marine Knowledge Exchange Network: outcomes from an innovative regional-to-national scale academic-led knowledge-to-impact network and recommendations for future initiatives. This issue.

Laffoley, D., and G. D. Grimsditch. 2009. The management of natural coastal carbon sinks. Gland, Switzerland: IUCN.

Lambert, D., L. Martins, and M. Ogborn. 2006. Currents, visions, and voyages: Historical geographies of the sea. Journal of Historical Geography 32 (3):479-93. doi: 10.1016/j.jhg.2005.10.004.

Langewiesche, W. 2004. The outlaw sea. New York: North Point Press.

Legge, O., M. Johnson, N. Hicks, T. Jickells, M. Diesing, J. Aldridge, J. Andrews, Y. Artioli, D. C. E. Bakker, M. T. Burrows, et al. 2020. Carbon on the northwest European shelf: Contemporary budget and future influences. Frontiers in Marine Science 7:143. doi:10.3389/fmars.2020.00143.

Lehahn, Y., K. N. Ingle, and A. Golberg. 2016. Global potential of offshore and shallow waters macroalgal biorefineries to provide for food, chemicals and energy: Feasibility and sustainability. Algal Research 17:150-60. doi: 10.1016/j.algal.2016.03.031.

Lindstad, H. E., and G. S. Eskeland. 2016. Environmental regulations in shipping: Policies leaning towards globalization of scrubbers deserve scrutiny. Transportation Research Part D: Transport and Environment 47:67-76. doi: 10.1016/j.trd.2016.05.004.

Macreadie, P. I., A. Anton, J. A. Raven, N. Beaumont, R. M. Connolly, et al. 2019. The future of blue carbon science. Nature Communications 10 (1):1-13.

Markus, T., H. Hillebrand, A. Hornidge, G. Krause, and A. Schlüter. 2018. Disciplinary diversity in marine sciences: The urgent case for an integration of research. ICES Journal of Marine Science 75 (2):502-9. doi: 10.1093/icesjms/fsx201.

Melaku Canu, D., A. Ghermandi, P. A. L. D. Nunes, P. Lazzari, G. Cossarini, and C. Solidoro. 2015. Estimating the value of carbon sequestration ecosystem services in the Mediterranean Sea: An ecological economics approach. Global Environmental Change 32:87-95. doi: 10.1016/j. gloenvcha.2015.02.008.

Palsson, G., B. Szerszynski, S. Sörlin, J. Marks, B. Avril, C. Crumley, H. Hackmann, P. Holm, J. Ingram, A. Kirman, et al. 2013. Reconceptualizing the "Anthropos" in the anthropocene: Integrating the social sciences and humanities in global environmental change research. Environmental Science \& Policy 28:3-13. doi: 10.1016/j.envsci.2012.11.004.

Pendleton, L., D. C. Donato, B. C. Murray, S. Crooks, W. A. Jenkins, S. Sifleet, C. Craft, J. W. Fourqurean, J. B. Kauffman, N. Marbà, et al. 2012. Estimating global "blue carbon" emissions from conversion and degradation of vegetated coastal ecosystems. PloS One 7 (9):e43542. doi: 10.1371/journal.pone.0043542.

Rockström, J., W. Steffen, K. Noone, A. Persson, F. S. Chapin, E. F. Lambin, T. M. Lenton, M. Scheffer, C. Folke, H. J. Schellnhuber, et al. 2009. A safe operating space for humanity. Nature 461 (7263):472-5. doi: 10.1038/461472a.

Rothwell, D. R., and T. Stephens. 2016. The international law of the sea. 2nd ed. Oxford \& Portland, Oregon: Hart Publishing.

Sands, P., J. Peel, A. Fabra, and R. MacKenzie. 2018. Principles of international environmental law. 4th ed. Cambridge: Cambridge University Press.

Smith, T., J. P. Jalkanen, B. A. Anderson, J. J. Corbett, J. Faber, et al. 2015. Third IMO GHG Study 2014, 327 pp. London, UK. Accessed November 17, 2017. http://www.imo.org/en/ OurWork/Environment/PollutionPrevention/AirPollution/Documents/Third\%20Greenhouse\% 20Gas\%20Study/GHG3\%20Executive\%20Summary\%20and\%20Report.pdf.

Steffen, W., K. Richardson, J. Rockstrom, S. E. Cornell, I. Fetzer, E. M. Bennett, R. Biggs, S. R. Carpenter, W. de Vries, C. A. de Wit, et al. 2015. Planetary boundaries: Guiding human development on a changing planet. Science (New York, N.Y.) 347 (6223):1259855. doi: 10.1126/science.1259855.

Steinacher, M., F. Joos, and T. F. Stocker. 2013. Allowable carbon emissions lowered by multiple climate targets. Nature 499 (7457):197-201. doi: 10.1038/nature12269.

Strong, A. L., J. J. Cullen, and S. P. Chisholm. 2009. Ocean fertilization: Science, policy, and commerce. Oceanography 22 (3):236-61. doi: 10.5670/oceanog.2009.83. 
Turner, L. M., R. Bhatta, L. Eriander, L. Gipperth, K. Johannesson, et al. 2017. Transporting ideas between marine and social sciences: Experiences from interdisciplinary research programs. Elementa Science of the Anthropocene 5:1-10. doi: 10.1525/elementa.148.

Turner, D. R., I.-M. Hassellöv, E. Ytreberg, and A. Rutgersson. 2017. Shipping and the environment: Smokestack emissions, scrubbers and unregulated oceanic consequences. Elementa Science of the Anthropocene 5:1-10. doi: 10.1525/elementa.167.

UNCTAD. 2017. Information Economy Report 2017. Digitalization, trade and development. Geneva: UNCTAD. Accessed October 04, 2017. http://unctad.org/en/PublicationsLibrary/ ier2017_en.pdf.

UNEP. 2013. Minimata Convention on Mercury. http://www.mercuryconvention.org/Convention/ Text/tabid/3426/language/en-US/Default.aspx

Wallace, D. W. R., C. S. Law, P. W. Boyd, Y. Collos, P. Croot, et al. 2010. Ocean fertilization. A scientific summary for policy makers, 17 pp. Paris: IOC/UNESCO (IOC/BRO/2010/2).

Watson, S. C., D. M. Paterson, A. M. Queirós, A. Rees, N. Stephens, S. Widdicombe, and N. J. Beaumont. 2016. A conceptual framework for assessing the ecosystem service of waste remediation: In the marine environment. Ecosystem Services 20:69-81. doi: 10.1016/j.ecoser.2016.06. 011.

Weichselgartner, J., and C. A. Marandino. 2012. Priority knowledge for marine environments: Grand challenges at the science-society nexus. Current Opinion in Environmental Sustainability 4 (3):323-330. doi: 10.1016/j.cosust.2012.05.001.

Wimmer, A., and N. Glick Schiller. 2002. Methodological nationalism and beyond: National state building migration and the social sciences. Global Networks 2 (4):301-334. doi: 10.1111/14710374.00043 .

Wöhrnschimmel, H., P. Tay, H. von Waldow, H. Hung, Y.-F. Li, M. Macleod, and K. Hungerbuhler. 2012. Comparative assessment of the global fate of $\alpha$ - and $\beta$-Hexachlorocyclohexane before and after phase-out. Environmental Science \& Technology 46 (4):2047-2054. doi: 10.1021/es203109q.

\section{Legal instruments (listed chronologically)}

Convention on the Preservation of Marine Pollution by Dumping of Wastes and Other Matter 1046 United Nations Treaty Series 120 (1972).

International Convention for the Prevention of Pollution by Ships 12 International Legal Materials 1319 (1973).

Protocol Relating to the Convention for the Prevention of Pollution from Ships 17 International Legal Materials 246 (1978).

Convention on Long-Range Transboundary Air Pollution 18 International Legal Materials 1442 (1979).

United Nations Convention on the Law of the Sea 21 International Legal Materials 1261 (1982).

Convention for the Protection of the Ozone Layer 26 International Legal Materials 1529 (1985).

Protocol on Substances that deplete the Ozone Layer 26 International Legal Materials 154 (1987).

Convention on Biological Diversity 31 International Legal Materials 822 (1992).

United Nations Framework Convention on Climate Change 31 International Legal Materials 849 (1992).

Protocol to the Convention on the Prevention of Marine Pollution by Dumping of Wastes and Other Matter 36 International Legal Materials 1 (1997).

Protocol to the 1979 Convention on Long Range Transboundary Air Pollution on Persistent Organic Pollutants 37 International Legal Materials 505 (1998).

Minamata Convention on Mercury (2013) http://mercuryconvention.org.

Directive (EU) 2016/802 of the European Parliament and of the Council of 11 May 2016 relating to a reduction in the sulphur content of certain liquid fuels Official Journal of the European Union L 132 (21 May 2016). 58-78. 